\title{
Effect of Thermocycling on Microhardness of Two Nanohybrid and One Microhybrid Composites Cured at Different Durations: An in vitro Study
}

\author{
${ }^{1}$ Geetha Ramachandran, ${ }^{2}$ Priya Madhusudanan, ${ }^{3}$ Rajesh Pillai, ${ }^{4}$ Nettiyat O Varghese, ${ }^{5}$ Sheila George, ${ }^{6} \mathrm{U}$-Nu Sujathan
}

\section{ABSTRACT}

Aim: The aim of this study was to evaluate the effect of thermocycling on microhardness of three composites cured at different durations.

Materials and methods: One hundred and twenty disks $(\mathrm{N}=$ 120) were made with a dimension of $5 \mathrm{~mm}$ diameter and $2 \mathrm{~mm}$ height using a metal mold from three composites (Filtek Z350 $\mathrm{XT}$, Tetric N Ceram, Z100 Universal Restorative). Forty disks each were made with each composite, which were again divided into two subgroups according to the duration of curing, 20 and 40 seconds. Microhardness test was done before and after thermocycling using Vickers microhardness test. Thermocycling was done at -5 and at $55^{\circ} \mathrm{C}$ for 250 cycles. Values were analyzed using analysis of variance (ANOVA) test, Tukey's simultaneous comparison.

Results: Among the groups cured for 40 seconds, in the control group, Z100 restorative showed higher microhardness. After thermocycling, even though there was a significant reduction in microhardness in all three composites, Tetric N Ceram showed minimal change in values compared with the other two composites.

Conclusion: It was concluded that after thermocycling, the composite resins are susceptible to significant reduction in microhardness.

Clinical significance: Patient's oral conditions, such as the cyclic thermal gradient and humidity can have negative effects on the mechanical properties of restorative materials. This is one of the factors contributing to a future need for replacement of dental restorative materials.

Keywords: Microhardness, Nanocomposites, Thermocycling.

How to cite this article: Ramachandran G, Madhusudanan P, Pillai R, Varghese NO, George S, Sujathan U-Nu. Effect of Thermocycling on Microhardness of Two Nanohybrid and One Microhybrid Composites Cured at Different Durations: An in vitro Study. Cons Dent Endod J 2018;3(1):27-33.

\footnotetext{
${ }^{1,2}$ Postgraduate Student, ${ }^{3}$ Professor and Head, ${ }^{4}$ Principal ${ }^{5}$ Professor, ${ }^{6}$ Reader

1-6Department of Conservative Dentistry and Endodontics, PMS College of Dental Science \& Research, Thiruvananthapuram Kerala, India

Corresponding Author: Geetha Ramachandran, Postgraduate Student, Department of Conservative Dentistry and Endodontics PMS College of Dental Science \& Research, Thiruvananthapuram Kerala, India, Phone: +919947341565, e-mail: geetha.r777@ gmail.com
}

\section{Source of support: Nil}

Conflict of interest: None

\section{INTRODUCTION}

The success of any restorative material depends upon its physical, chemical, and mechanical properties. Concerns related to mercury in dental amalgam, and a pursuance for improved esthetics in dental restorations, have shifted researchers' interest to resin composites as a permanent alternative to metallic restorations.

Composite resins are one of the widely used esthetic restorative materials. The major components of composite resins are organic phase (matrix), dispersed phase (filler), a coupling agent (organosilane), activator-initiator system and inhibitors, along with other minor constituents.

Filler particles enhance the hardness, manipulation, and reduce the dimensional changes in composites. ${ }^{1}$ Although both organic and inorganic phases might influence the material behavior, the features of filler particles and rate of curing are the most important factors related to an improvement in the mechanical properties of the resin composites. The degree of cure of visible light-activated dental resins is an important parameter affecting the clinical success of these materials as was found out soon after these materials were introduced. ${ }^{2,3}$

Hardness or microhardness is often traditionally used as an indirect measurement of effectiveness of composite cure or the degree of conversion. ${ }^{4}$ Hardness is defined as the resistance of a material to indentation or penetration. It determines the wear resistance of a material and the extent to which it will abrade or be abraded by opposing structures.

Surface hardness can be measured on the upper and lower surfaces of disk-shaped specimens with a given thickness. Microhardness measurements, though, are affected not only by the degree of resin conversion, but also by the type.

In thermocycling, simulation of thermal stresses generated in teeth and restorative materials is done. ${ }^{5}$ The samples to be tested are immersed in hot and cold distilled water alternately for predetermined duration and number of cycles. ${ }^{6,7}$ 
Previous researches have concluded that thermocycling induces structural damage of surface of composites. On a microscopic scale, cracks are seen to be produced .These are attributed to the thermal shock created among the constituents in the composite. ${ }^{8,9}$ Therefore, the assessment of the mechanical properties of composites exposed to thermocycling process is important.

In this study, the aim was to evaluate the effect of curing time on the microhardness of composites. Also, the effects of thermocycling process on microhardness of nanocomposites compared with microhybrid composite is studied.

\section{MATERIALS AND METHODS}

Three resin composites were selected for the present study and were chosen in accordance with their type of filler particles: Two nanohybrid (Filtek Z350 XT, Tetric N Ceram) and one microhybrid (Z100 Universal Restorative) composites (Fig. 1). The materials and their manufacturers are as shown in Table 1.

A total of 120 disk-shaped specimens ( $5 \mathrm{~mm}$ diameter $\times 2 \mathrm{~mm}$ height) from the three resin composites were fabricated using a metallic mold at room temperature. The resin composite material was gently packed inside the mold which rested on a glass slab. The lower surfaces of the unpolymerized specimen were covered with thin Mylar strips to avoid oxygen inhibition and to avoid air entrapment.

A second Mylar strip and glass slab were stabilized in contact with the uncured composite and pressed to the thickness of the mold. Glass slabs were used to provide flat specimens with a uniform surface that would be less likely to introduce variations in the microhardness measurements. The glass slab was compressed carefully on top of the specimen to remove the excess of the material giving a flat surface.

From each composite, 40 disks were made.

Curing was done by irradiating the resin composites using light-emitting diode lamp with light probe diameters of $8 \mathrm{~mm}$. The cordless curing unit was maintained at full charge before use. Twenty disks of each composite were cured for 20 seconds and the other 20 for 40 seconds (Fig. 2).

The distal end of the light guide was placed at $90^{\circ}$ against the surface of the matrix strip at about $1 \mathrm{~mm}$ distance and positioned concentrically with the mold; and, the material was then light-cured from the top. The hardened specimens were then removed from the mold and lightly finished manually from both sides after the preparation. This finishing procedure was carried out with 1,000 grit

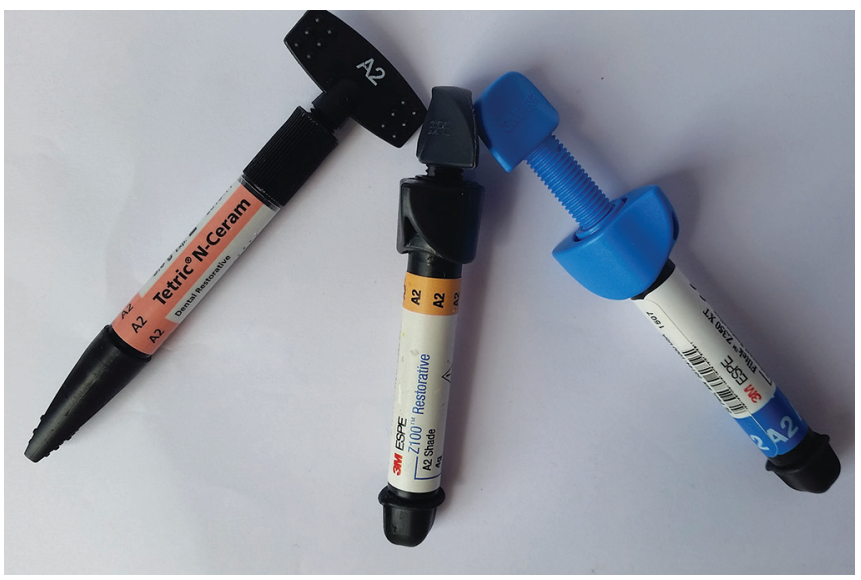

Fig. 1: Composites used

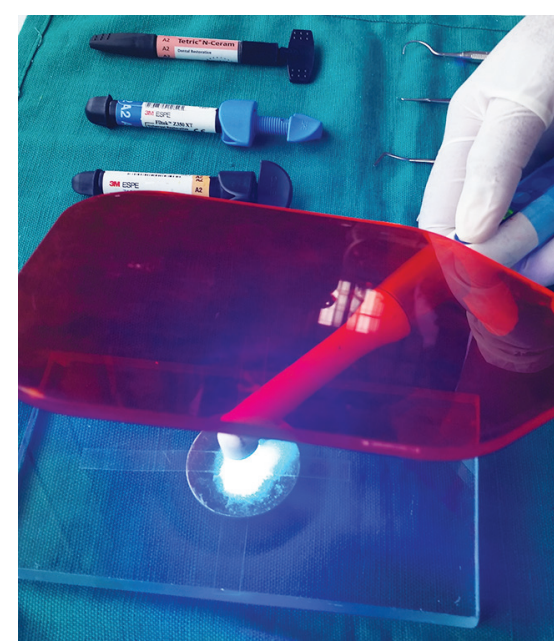

Fig. 2: Curing of samples

Table 1: Constituents of the materials

\begin{tabular}{|c|c|c|c|c|c|c|}
\hline Material & Code & Category & Resin matrix & Particle size (mean) & Filler type & Filler content \\
\hline $\begin{array}{l}\text { Filtek Z350XT } \\
\text { (3M ESPE, St } \\
\text { Paul, MN, USA) }\end{array}$ & $\mathrm{F}$ & $\begin{array}{l}\text { Nanohybrid } \\
\text { (Shade A2) }\end{array}$ & $\begin{array}{l}\text { Urethane dimethacrylate, } \\
\text { bisphenol A diglycidyl } \\
\text { methacrylate, TEGDMA, } \\
\text { poly(ethylene glycol)- } \\
\text { dimethacrylate }\end{array}$ & $\begin{array}{l}20 \mathrm{~nm} \text { silica filler, } \\
4-11 \mathrm{~nm} \text { zirconia } \\
\text { filler }\end{array}$ & $\begin{array}{l}\text { Zirconia/silica } \\
\text { nanoclusters, silica } \\
\text { nanoparticles, zirconia } \\
\text { nanoparticles }\end{array}$ & $73 \mathrm{vol} \%$ \\
\hline $\begin{array}{l}\text { Tetric N Ceram } \\
\text { [(Ivoclar Vivadent) }\end{array}$ & $\mathrm{T}$ & $\begin{array}{l}\text { Nanohybrid } \\
\text { (Shade A2) }\end{array}$ & Dimethacrylates $19-20$ wt\% & $\begin{array}{l}\text { Filler size (40- } \\
3,000 \mathrm{~nm})\end{array}$ & $\begin{array}{l}\text { Barium glass, YtF, } \\
\text { mixed oxides and } \\
\text { copolymers }\end{array}$ & $\begin{array}{l}(80-81 \text { wt } \%) \\
55-57 \text { vol\% }\end{array}$ \\
\hline $\begin{array}{l}\text { Z100 Restorative } \\
\text { (3M ESPE, St } \\
\text { Paul, MN, USA) }\end{array}$ & Z & $\begin{array}{l}\text { Microhybrid } \\
\text { (Shade A2) }\end{array}$ & Bis-GMA, TEGDMA resins & $3.5-0.01 \mu \mathrm{m}$ & Zirconia/silica & 66 vol\% \\
\hline
\end{tabular}


Effect of Thermocycling on Microhardness of Two Nanohybrid

Table 2: Grouping of materials

\begin{tabular}{|c|c|c|c|c|c|c|c|c|c|c|c|}
\hline \multicolumn{12}{|c|}{ Microhardness } \\
\hline \multicolumn{6}{|c|}{ Control (C) } & \multicolumn{6}{|c|}{ Experimental (Thermocycled) (T) } \\
\hline \multicolumn{3}{|c|}{$20 \mathrm{sec}$} & \multicolumn{3}{|c|}{$40 \mathrm{sec}$} & \multicolumn{3}{|c|}{$20 \mathrm{sec}$} & \multicolumn{3}{|c|}{$40 \mathrm{sec}$} \\
\hline \multicolumn{3}{|c|}{ Group 1} & \multicolumn{3}{|c|}{ Group 2} & \multicolumn{3}{|c|}{ Group 3} & \multicolumn{3}{|c|}{ Group 4} \\
\hline $\mathrm{F} 2 \mathrm{C}$ & $\mathrm{Z2C}$ & $\mathrm{T} 2 \mathrm{C}$ & $\mathrm{F} 4 \mathrm{C}$ & $\mathrm{Z4C}$ & $\mathrm{T} 4 \mathrm{C}$ & $\mathrm{F} 2 \mathrm{~T}$ & Z2T & $\mathrm{T} 2 \mathrm{~T}$ & F4T & Z4T & $\mathrm{T} 4 \mathrm{~T}$ \\
\hline \multicolumn{12}{|c|}{30 samples in each group } \\
\hline & & & & & $\mathrm{al}=1$ & amples & & & & & \\
\hline
\end{tabular}

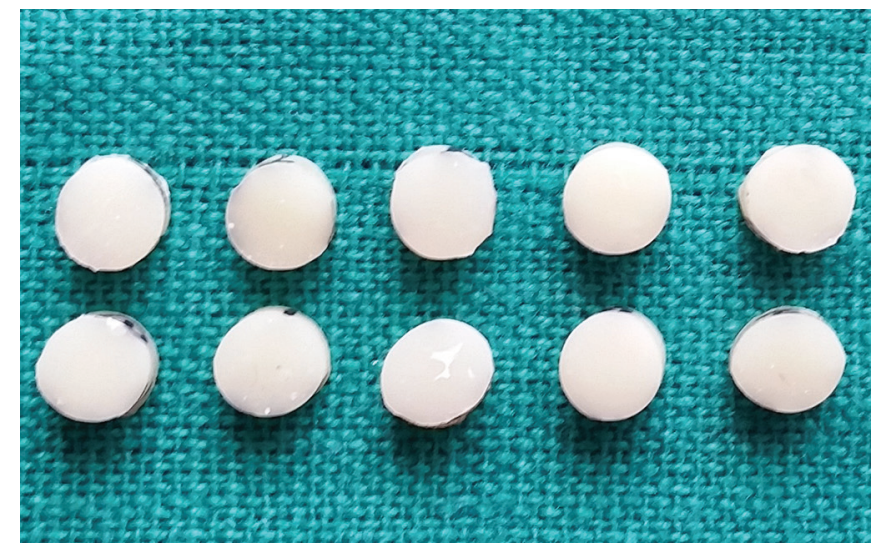

Fig. 3: Samples in a group

silicon carbide abrasive paper under running coolant water followed by polishing with 2,000 grit silicon carbide paper as well as Shofu composite polishing kit.

This will allow removal of a weak resin-rich layer giving a smooth, flat testing surface. Thereafter, the examined surface was assessed for any major defects or scratches by stereo microscope.

\section{Grouping}

A total of 120 samples were made from the three composites. They were divided into control and experimental groups $(n=60)$. They were again divided into subgroups (Table 2), with 10 samples each (Fig. 3) based on the curing time of 20 seconds and 40 seconds. In the experimental group, samples underwent thermocycling.

\section{Methodology}

In the control group, after preparation of samples at different curing times, microhardness test was done. In the experimental group, microhardness test was done following thermocycling.

\section{Vickers Microhardness Testing}

The test was carried out at Sree Chitra Institute, Thiruvananthapuram. The baseline surface microhardness values were recorded using a Vickers hardness tester (Fig. 4)

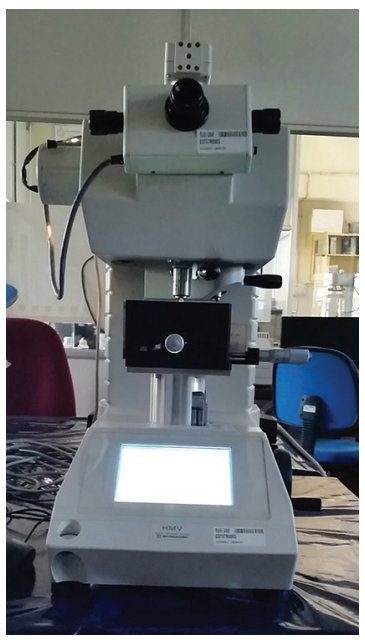

Fig. 4: Microhardness tester

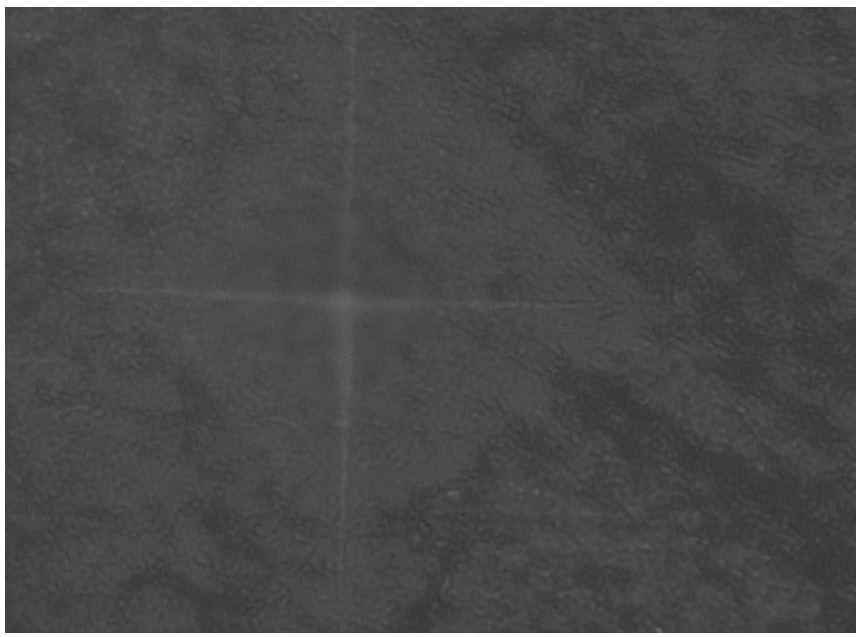

Fig. 5: Indentation of microhardness tester on sample

having a diamond pyramid microindenter (Fig. 5).

The test was conducted at room temperature with a load of $300 \mathrm{~g}$ with a dwell time of 15 seconds. Three indentations, $1 \mathrm{~mm}$ apart, were made on the irradiated surface of the specimen and averaged to yield a single microhardness number.

The indentations were observed through optical microscope at a magnification of $50 \times$.

\section{Thermocycling}

Thermocycling (Fig. 6) was done between -5 and $55^{\circ} \mathrm{C}$ with a dwell time of 30 seconds. Cold cycle was of tem- 


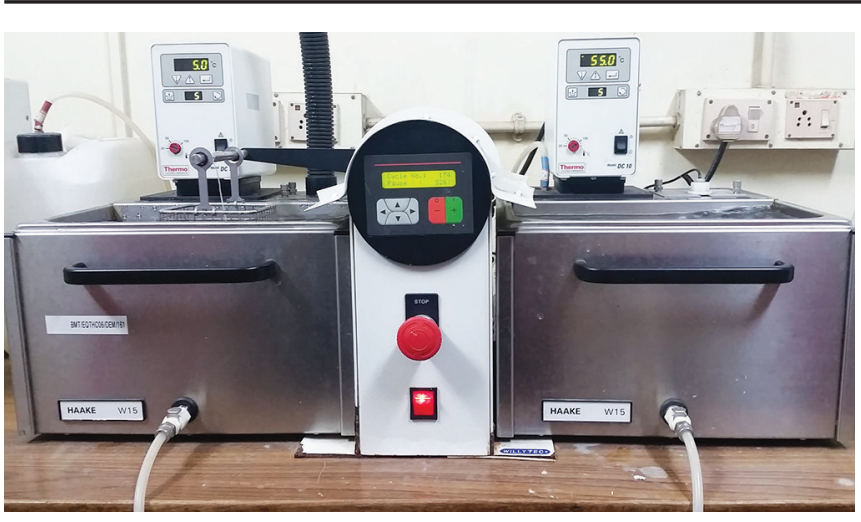

Fig. 6: Thermocycler

perature $-5^{\circ} \mathrm{C}$ with a dwell time 30 seconds, dry cycle at $22^{\circ} \mathrm{C}$ with a dwell time 5 seconds. Temperature of hot cycle was $55^{\circ} \mathrm{C}$ with dwell time 30 seconds. The total number of cycles was 250 .

\section{Statistical Analysis}

One-way ANOVA test was performed to examine the statistical difference between the groups.

The mean value and standard deviation of each composite is shown in Table 3. Mean value for the 120 samples is 66.57. The ANOVA value is 274.76 , and p-value is 0.000 (less than $5 \%$ ) which is statistically significant. Thus, there is statistically significant difference existing among the groups.

Tukey's simultaneous comparison test (Table 4 and Graph 1) was done to determine mean values that are significantly different from each other. As seen from Table 4, the critical value obtained is 3.34 . Those groups in which

\begin{tabular}{|c|c|c|c|c|c|}
\hline \multicolumn{6}{|c|}{ One-factor ANOVA } \\
\hline & Mean & $n$ & $\begin{array}{l}\text { Standard } \\
\text { deviation }\end{array}$ & & \\
\hline & 70.28 & 10.00 & 5.08 & $\mathrm{~F} 2 \mathrm{C}$ & \\
\hline & 80.72 & 10.00 & 4.37 & $\mathrm{~F} 4 \mathrm{C}$ & \\
\hline & 62.98 & 10.00 & 3.88 & $\mathrm{~F} 2 \mathrm{~T}$ & \\
\hline & 74.22 & 10.00 & 5.29 & F4T & \\
\hline & 87.39 & 10.00 & 4.13 & $\mathrm{Z} 2 \mathrm{C}$ & \\
\hline & 96.98 & 10.00 & 2.92 & Z4C & \\
\hline & 82.83 & 10.00 & 5.77 & Z2T & \\
\hline & 89.59 & 10.00 & 5.50 & Z4T & \\
\hline & 37.57 & 10.00 & 3.12 & $\mathrm{~T} 2 \mathrm{C}$ & \\
\hline & 44.47 & 10.00 & 4.11 & $\mathrm{~T} 4 \mathrm{C}$ & \\
\hline & 30.72 & 10.00 & 0.92 & T2T & \\
\hline & 41.07 & 10.00 & 4.67 & $\mathrm{~T} 4 \mathrm{~T}$ & \\
\hline & 66.57 & 120.00 & 22.28 & Total & \\
\hline Source & SS & $d f$ & MS & $F$ & $p$-value \\
\hline Treatment & $57,033.65$ & 11.00 & $5,184.88$ & 274.76 & 0.000 \\
\hline Error & $2,038.02$ & 108.00 & 18.87 & Result & Significant \\
\hline Total & $59,071.67$ & 119.00 & & & \\
\hline
\end{tabular}

the value falls below the value of 3.34 do not show any statistically significant difference (e.g., T4T and T2C, T4C and T4T, etc.). All other values are found to be statistically significant. Values nearer to critical value of 3.43 [marked * or light blue] are statistically significant at $5 \%$, whereas the values dark blue marked ${ }^{* *}$ are significant at $1 \%$.

From the table, it was concluded that there was no statistically significant difference in values between control (T4C) and experimental (T4T) groups of Tetric N Ceram.

Table 4: Tukey's test values

\begin{tabular}{|c|c|c|c|c|c|c|c|c|c|c|c|c|c|}
\hline \multicolumn{14}{|c|}{ Tukey simultaneous comparison $t$-values $(d f=108)$} \\
\hline & & $\mathrm{T} 2 \mathrm{~T}$ & $\mathrm{~T} 2 \mathrm{C}$ & $\mathrm{T} 4 \mathrm{~T}$ & $\mathrm{~T} 4 \mathrm{C}$ & $\mathrm{F} 2 \mathrm{~T}$ & $\mathrm{~F} 2 \mathrm{C}$ & F4T & $\mathrm{F} 4 \mathrm{C}$ & Z2T & $\mathrm{Z2C}$ & Z4T & Z4C \\
\hline & & 30.72 & 37.57 & 41.07 & 44.47 & 62.98 & 70.28 & 74.22 & 80.72 & 82.83 & 87.39 & 89.59 & 96.98 \\
\hline \multicolumn{14}{|l|}{$\mathrm{T} 2 \mathrm{~T}$} \\
\hline $\mathrm{T} 2 \mathrm{C}$ & 37.57 & $3.53^{*}$ & & & & & & & & & & & \\
\hline T4T & 41.07 & $5.33^{* *}$ & 1.80 & & & & & & & & & & \\
\hline $\mathrm{T} 4 \mathrm{C}$ & 44.47 & 7.08 & $3.55^{\star}$ & 1.75 & & & & & & & & & \\
\hline $\mathrm{F} 2 \mathrm{~T}$ & 62.98 & 16.60 & 13.08 & 11.28 & 9.53 & & & & & & & & \\
\hline $\mathrm{F} 2 \mathrm{C}$ & 70.28 & 20.36 & 16.84 & 15.04 & 13.28 & 3.76 & & & & & & & \\
\hline $\mathrm{F} 4 \mathrm{~T}$ & 74.22 & 22.39 & 18.87 & 17.07 & 15.31 & 5.79 & 2.03 & & & & & & \\
\hline $\mathrm{F} 4 \mathrm{C}$ & 80.72 & 25.74 & 22.21 & 20.41 & 18.66 & 9.13 & 5.38 & 3.35 & & & & & \\
\hline Z2T & 82.83 & 26.82 & 23.30 & 21.50 & 19.75 & 10.22 & 6.46 & 4.43 & 1.08 & & & & \\
\hline $\mathrm{Z} 2 \mathrm{C}$ & 87.39 & 29.17 & 25.65 & 23.85 & 22.09 & 12.57 & 8.81 & 6.78 & 3.43 & 2.35 & & & \\
\hline Z4T & 89.59 & 30.30 & 26.78 & 24.98 & 23.22 & 13.70 & 9.94 & 7.91 & 4.56 & 3.48 & 1.13 & & \\
\hline Z4C & 96.98 & 34.11 & 30.58 & 28.78 & 27.03 & 17.50 & 13.75 & 11.72 & 8.37 & 7.29 & 4.94 & 3.81 & \\
\hline
\end{tabular}

Critical values for experiment-wise error rate

$0.05 \quad 3.34$ 


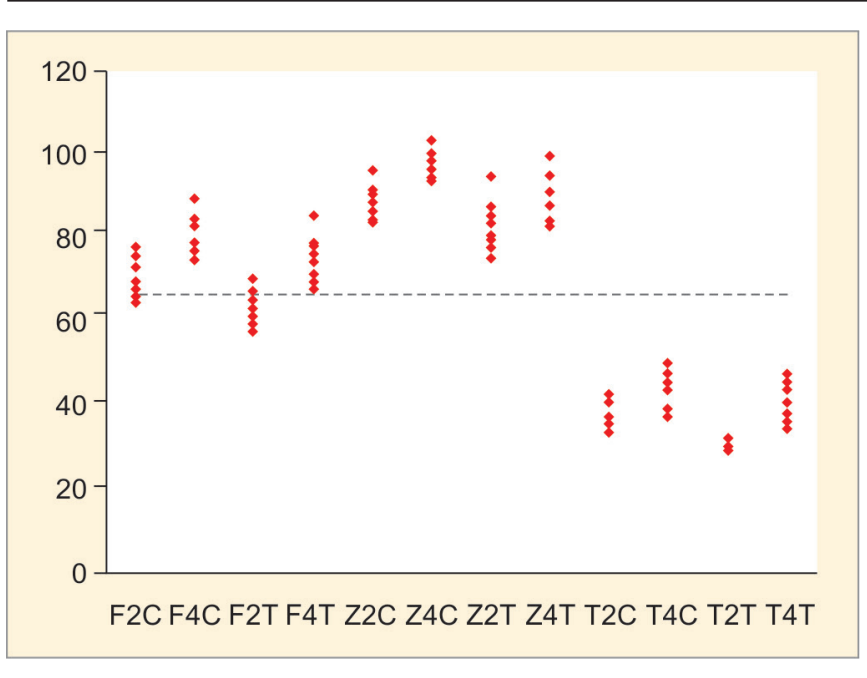

Graph 1: Tukey's comparison test

\section{RESULTS}

From Graph 1, it can be appreciated that

- There was a statistically significant increase in microhardness values when the curing time was increased from 20 to 40 seconds in all the three composites.

- In all the composites, the control group showed higher values of microhardness than the experimental group (thermocycled).

- Z100 Universal showed the highest microhardness values in both control and experimental groups, followed by Filtek Z350 XT, and least was for Tetric N Ceram.

- Change in microhardness values following thermocycling was minimal for Tetric N Ceram.

\section{DISCUSSION}

The decision to choose a particular resin composite in a given clinical situation requires the evaluation of its functional characteristics. Factors to be considered include the enhanced longevity, which in turn depends on mechanical properties, such as strength, fracture toughness, surface hardness, modulus of elasticity, wear, water sorption, solubility, and polymerization shrinkage, to name a few.

Previous research studies have demonstrated that contributing factors to the degree of polymerization of light-cured resin composites include the type and amount of monomers, filler, initiator-catalyst, the wavelength of curing light used, intensity of irradiation, and duration of curing. ${ }^{10}$

Hardness of resin composites affects the capability of polishing and resistance to scratches of the material. ${ }^{11}$ The ability of material to abrade or to be abraded by opposing dental structures, materials, or any chemical softening has implications for clinical durability of dental restorations. ${ }^{12,13}$
In the present study, highest microhardness values were found for microhybrid composite.

This may be due to the larger particle size and hardness of zirconia and silica filler particles.

Consequently, the specific surface between fillers and organic matrix is lowered, thus reducing light scattering, leading to better polymerization and hardness.

The higher microhardness value of Filtek Z350 XT compared with Tetric N Ceram in the present study might be attributed to the presence of nanofillers and nanoclusters which could affect the light reflection and hence, the degree of conversion.

The smaller the size of filler particles, the higher the light scattering occurs.

As the light strikes the composite material, significant attenuation occurs due to scattering and reflection within the material. Thus, the degree of polymerization is affected, finally lowering the microhardness values. ${ }^{14}$

Also, the zirconia and silica fillers in Filtek Z350XT have greater hardness and less solubility when compared with fillers in Tetric N Ceram (Barium). Barium fillers do not attach to the matrix readily in comparison with Filtek Z350XT where matrix filler complex is better adapted. $^{15}$

Larger filler size variation in Tetric NCeram (40-160 nm) might also explain lesser microhardness value when com-

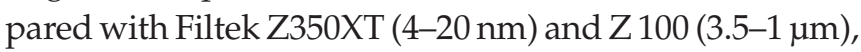
because it affects light scattering.

Two factors can have influence on mechanical properties of samples exposed to thermocycling process. These are:

1. The effect of curing time

2. Thermal stresses generated due to thermal gradient in thermocycling process among structural constitutions of composites. ${ }^{16}$

Thermocycling is an experimental process to simulate the real oral thermal conditions. The temperature changes induced by alternate intake of hot and cold foods may contribute to failure of composites resins by affecting cohesion. The difference in thermal expansion coefficients between the organic matrix and inorganic filler particles results in impaired cohesion.

The negative influence of water on composites can be explained by two different mechanisms. First, water influences the material behavior by converting it from an elastic to plastic state. As a consequence, the matrix volume of the nanocomposite is seen to increase. Also, there is significant decrease in stiffness of the material.

The second mechanism is due to the probable dissolution of components of composite in water.

Medina Tirado et $\mathrm{al}^{17}$ indicated that thermocycling has negative effects on the hardness of some dental 
composites. This is similar to the findings in the present study.

Nanofilled composites release more triethylene glycol dimethacrylate (TEGDMA) (monomer) than microhybrid composites. So, they may present higher degradation in the oral environment than hybrid ones. This happens as the result of water sorption which leads to monomer elution. ${ }^{18}$

In the present study, decrease in microhardness following thermocycling, was minimal for Tetric N Ceram. This may be attributed to the absence of TEGDMA in Tetric N Ceram.

In addition, the theoretically larger total surface area of nanofiller particles allows more water to accumulate at the filler particle-polymeric matrix interfaces, thus increasing water sorption. Water may accumulate at the aggregated zirconia/silica cluster filler-organic matrix interface in the Filtek Z350 XT composite and can create paths for water diffusion toward the inside of aggregates, where microvoids are probably present due to lack of 5- to 20-nm-sized primary particles being impregnated in the polymeric matrix. ${ }^{19}$

In the present study, microhardness was shown to increase with increase in curing time. This occurs because increasing the light curing time means increasing the total energy delivered to the resin composite increment. This increase may partly compensate for the energy loss due to dispersion of light resulting from an increase in distance between the resin composite and the tip of the light curing unit. $^{20}$

Thus it has been shown that microhardness of composite resins varies depending on the filler content, curing time, and thermocycling.

\section{CONCLUSION}

Within the limitations of this in vitro study, the following conclusions can be drawn:

- Thermocycling composites at varied temperatures decrease the surface microhardness.

- Increasing the duration of photopolymerization of the composites investigated increases the surface microhardness.

- The different filler content of the two composites does affect their surface microhardness.

- Photopolymerization time of 40 seconds is recommended for the composites to impart better wear resistance.

\section{CLINICAL SIGNIFICANCE}

Patient's oral conditions, such as the cyclic thermal gradient and humidity can have negative effects on the mechanical properties of restorative materials. This is one of the factors contributing to a future need for replacement of dental restorative materials.

\section{REFERENCES}

1. Cunha LG, Sinhoreti MA, Consani S, Sobrino LC. Effect of different photoactivation methods on the polymerization depth of a light-activated composite. Oper Dent 2003 Mar-Apr; 28(2):155-159.

2. Imazato S, Tarumi H, Kobayashi K, Hiraguri H, Oda K, Tsuchitani Y. Relationship between the degree of conversion and internal discoloration of light-activated composite. Dent Mater J 1995 Jun;14(1): 23-30.

3. Cavalcante LM, Peris AR, Amaral CM, Ambrosano GM, Pimenta LA. Influence of polymerization technique on microleakage and microhardness of resin composite restorations. Oper Dent 2003 Mar-Apr;28(2):200-206.

4. Kim KH, Ong JL, Okuno O. The effect of filler loading and morphology on the mechanical properties of contemporary composites. J Prosthet Dent 2002 Jun;87(6):642-649.

5. Litkowski LJ, McDonald NJ, Swierczewski M. A comparison of thermalcycling methods for evaluation microleakage. J Dent Res 1989;68:207.

6. Pereira SMB, Castilho AA, Salazar-MarochoSM, Oliveira KMC, Váquez VZC, Bottino MA. Thermocycling effect on microhardness of laboratory composite resins. Braz J Oral Sci 2007;6(22).

7. Souza RO, Ozcan M, Michida SM, de Melo RM, Pavanelli CA, Bottino MA, Soares LE, Martin AA. Conversion degree of indirect resin composites and effect of thermocycling on their physical properties. J Prosthodont 2010 Apr;19(3): 218-225.

8. Y1lmaz EC, Sadeler R. Effect of thermal cycling and microhardness on roughness of composite restorative materials. J Restorative Dent 2016;4(3):93-96.

9. Okida RC, Da Silveira Okida DS. Effect of thermocycling on the color stability of different shades of composite resins, Int J Clin Dent 2013 Nov;6(4):341.

10. Sakaguchi RL, Douglas WH, Peters MC. Curing light performance and polymerization of composite restorative materials. J Dent 1992 Jun;20(3):183-188.

11. Erickson RL, Barkmeier WW, Halvorson RH. Curing characteristics of a composite-Part 1: Cure depth relationship to conversion, hardness and radiant exposure. Dent Mater 2014 Jun;30(6):e125-e133.

12. Polydorou O, Mönting JS, Hellwig E, Auschill TM. Effect of inoffice tooth bleaching on the microhardness of six dental esthetic restorative materials. Dent Mater 2007 Feb;23(2):153-158.

13. Campos I, Briso AL, Pimenta LA, Ambrosano G. Effects of bleaching with carbamide peroxide gels on microhardness of restoration materials. J Esthet Restor Dent 2003;15(3): 175-182.

14. Turssi CP, Ferracane JL, Vogel K. Filler features and their effects on wear and degree of conversion of particulate dental resin composites. Biomaterials 2005 Aug;26(24):4932-4937.

15. Abuelenain DA, Neel EAA, Al-Dharrab A. Surface and mechanical properties of different dental composites. Austin J Dent 2015;2(2):1019.

16. Karimzadeh A, Ayatollahi MR, Asgharzadeh Shirazi H. Mechanical properties of a dental nano-composite in moist media determined by nano-scale measurement. Int J Mater Mech Manufacturing 2014 Feb;2(1):67-72. 
17. Medina Tirado JI, Nagy WW, Dhuru VB, Ziebert AJ. The effect of thermocycling on the fracture toughness and hardness of core buildup materials. J Prosthet Dent 2001 Nov;86(5): 474-480.

18. Villalta P, Lu H, Okte Z, Garcia-Godoy F, Powers JM. Effects of staining and bleaching on color change of dental composite resins. J Prosthet Dent 2006 Feb;95(2):137-142.
19. Tabatabaee MH, Arami S, Ghavam M, Rezaii A. Monomer release from nanofilled and microhybrid dental composites after bleaching. J Dent Tehran Univ Med Sci 2014 Jan;11(1):56-66.

20. Aguiar FHB, Braceiro A, Lima DANL, Ambrosano GMB, Lovadino JR. Effect of light curing modes and light curing time on the microhardness of a hybrid composite resin. J Contemp Dent Pract 2007 Sep;6(8):001-008. 